\title{
Seraïdari Katerina, La ville, la nation et l'immigré. Rapports entre Grecs et Turcs à Bruxelles
}

Iris Polyzos

\section{(2) OpenEdition \\ 12 Journals}

Édition électronique

URL : https://journals.openedition.org/remi/7332

DOI : $10.4000 /$ remi. 7332

ISSN : $1777-5418$

Éditeur

Université de Poitiers

Édition imprimée

Date de publication : 1 juin 2015

Pagination : 142-143

ISBN : 979-10-90426-25-2

ISSN : 0765-0752

Référence électronique

Iris Polyzos, « Seraïdari Katerina, La ville, la nation et l'immigré. Rapports entre Grecs et Turcs à Bruxelles ", Revue européenne des migrations internationales [En ligne], vol. 31 - n² | 2015, mis en ligne le 01 juin 2015, consulté le 15 avril 2022. URL : http://journals.openedition.org/remi/7332 ; DOI : https://doi.org/10.4000/remi.7332 
Seraïdari, Katerina

La ville, la nation et l'immigré. Rapports entre Grecs et Turcs à Bruxelles -

Paris : L'Harmattan, $2012-218$ p. ISBN : 978-2-336-00325-2

Cet ouvrage étudie comment les perceptions et les préjugés des migrants sont modifiés et reformulés après l'immigration, comment leur présence " interroge " la ville, voir même l'Étatnation d'arrivée. Pour répondre à ces questionnements, Katerina Seraïdari compare les rapports que deux groupes migratoires, les migrants grecs et turcs, entretiennent avec la ville et le pays d'installation. Le contexte spatial de cette enquête est la ville de Bruxelles et le cadre temporel débute dans les années 1960 et s'étend jusqu'aux années 1980. L'intérêt particulier que présente l'étude de ce deux " communautés " est lié aux relations historiques et complexes qu'entretiennent ces migrants avec leur pays d'origine : ces " communautés " peuvent-elles bâtir des relations fortes et comment ces relations se modifient-elles dans le cadre d'une mobilité ascendante dans la société d'accueil ?La question centrale que l'auteure souhaite explorer est si les rapports entre ces deux groupes permettent de repenser les dits " différends " qu'existent entre la Grèce et laTurquie : " dans quelle mesure ces immigrés grecs et turcs, qui se sont trouvés relégués dans les mêmes quartiers ou les mêmes emplois, ont-ils été enclins à développer des liens de sociabilité ?" (p. 13).

Dans la première partie, l'auteure introduit le contexte théorique et les principaux concepts. En premier lieu, quoique selon son expression il n'y " pas de problèmes " aigus entre les deux groupes, elle discerne trois principaux types de rapport de " vivre ensemble " : confrontation-hostilité, affinité et indifférence. Cette typologie, qui prend une place centrale dans son analyse, est mobilisée pour décrire l'ensemble des interactions entre migrants grecs et turcs.
En deuxième lieu, Seraïdari met l'accent sur l'importance que jouent les représentations et, notamment, sur les processus d'auto- et d'hétéro-définition des migrants au sein de la société d'accueil. Elle souligne que ces représentations sont fortement liées au pays d'origine, mais aussi à celui d'arrivée. Ainsi, le schéma entre les " pays du nord - travailleurs " et les "pays du sud - paresseux ", influence fortement les stéréotypes face aux " communautés " grecques et turques de Bruxelles. L'auteure souhaite donc montrer que " I'habitus national " conditionne les comportements des migrants quoique, au final, ils puissent manipuler ou modifier leurs " référents identitaires selon leurs intérêts et leur positionnement $»$ (p. 41).

En troisième lieu, à travers l'exemple de l'alimentation, qui compose un champ investi par ces deux groupes et qui en même temps constitue/ forme un espace où les définitions ethniques et identitaires se remodèlent, Seraïdari conclut que les processus de catégorisation se font à travers trois types de relations : les relations à l'intérieur du groupe, où des fortes différenciations économiques et régionales se manifestent, les relations que le groupe de migrants tisse avec la " société-hôte ", puis les relations entre différents groupes migratoires.

Dans la deuxième partie, composée de dix chapitres, l'auteure suit, à travers les récits de vie d'interlocuteurs privilégiés, les processus d'installation des migrants grecs et turcs à Bruxelles. Elle souligne le passage progressif du travail dépendant - principalement dans les mines - au travail indépendant - essentiellement dans le petit commerce et la restauration - qui fait son apparition dans les grandes villes de Belgique. Dans les chapitres cinq et six, Seraïdari essaie de tracer les rapports entre ces deux communautés à travers les quartiers d'habitat et les principaux lieux de fréquentation, tels que les cafétérias, les bars et d'autres lieux de sociabilité. Elle montre que les représentations jouent un 
rôle décisif pour définir un lieu, en l'occurrence comme un "quartier turc " ou un " quartier grec " C'est à travers l'introduction des " marqueurs dans l'espace " que les migrants gagnent une forte visibilité. Dans ces mêmes chapitres, elle insiste sur les interactions qui se tissent au sein des activités ethniques et, surtout, entre les commerçants et leur clientèle.

Au final, cette partie revient sur la problématique principale de l'ouvrage concernant les relations entre ces deux groupes: " dans quelle mesure les commerçants grecs et turcs brouillent-ils les frontières séparant ces groupes et leurs référents identitaires ? " (p. 142). Pour y répondre, l'auteure analyse brièvement l'évolution de l'immigration turque et grecque vers la Belgique dans les années 1970-1980 : tandis que la première se poursuit et connaît une dynamique avec l'arrivée des nouveaux vagues migratoires, la seconde cesse d'augmenter. En parallèle, les migrants grecs déjà établis présentent une mobilité résidentielle ascendante et s'éloignent des premiers espaces d'installation. Ces évolutions produisent une certaine distance sociale entre les deux groupes étudiés.

L'ouvrage possède plusieurs qualités. Il est investi d'un riche recueil de données ethnographiques et, parmi ces données, les récits de vie tiennent une place importante. L'auteure montre une connaissance approfondie de ces deux groupes migratoires et réussit de transmettre aux lecteurs les spécificités de leur installation en Belgique. Le fait que I' analyse de l'immigration grecque et turque porte sur une longue période, permet de mieux tracer l'évolution des parcours migratoires, ainsi que celle de la deuxième, voir même de la troisième génération. À coté de ces qualités, il faut noter que certains aspects sont moins approfondis. L'approche théorique de l'ouvrage n'est pas suffisamment définit ce qui ne permet pas de le situer au sein d'un débat scientifique plus large. Puis, quoiqu'un des objectifs de l'étude soit l'analyse des rapports entre ville et immigration, nous trouvons peu d'éléments sur le contexte sociospatial des quartiers d'installation, ainsi que sur les modes et les conditions d'habitat. Des cartes de localisation auraient pu contribuer à la meilleure compréhension des quartiers bruxellois où se situent les deux groupes migratoires.

Au final, I'ouvrage de Katerina Seraïdari présente un grand intérêt puisque il contribue à la compréhension des rapports interethniques à travers le prisme des représentations. Le choix d'analyser ces deux groupes spécifiques produit des données originales et montre que, finalement, les points en communs entre les " communautés " grecques et turques sont bien plus nombreux.

Iris Polyzos

Docteur en géographie, membre scientifique à l'École française d'Athènes 